\title{
Blend response of four Egyptian cotton population types for late planting stress tolerance
}

\author{
Khaled M. A. Baker ${ }^{1}$ and Sara E. I. Eldessouky ${ }^{2^{*}}$ (D)
}

\begin{abstract}
Background: This study was conducted to investigate the effect of heterogeneity and heterozygosity on lint yield and fiber quality of Egyptian cotton for late planting stress tolerance. Lint yield was recorded in two planting dates among four cotton population types which included homozygous lines grown in pure stands, hybrids grown in pure stands, homozygous lines in blended stands, and hybrids grown in blended stands. Comparisons were made using trait means, blend response, and heterotic response. Stress susceptibility index (SSI) was calculated over planting dates.

Results: In normal planting date, the results showed that means of lint yield for homozygous entries (population I and II) were greater than mean yields of heterozygous entries (population III and IV). In late planting date, the results showed that mean of lint yield for some homozygous entries was equal mean yields of heterozygous entries. Regarding the yield, there was no significant difference between inbreds and blend of hybrids. However, the heterozygous populations had a lower (SSI) and more tolerance for late planting than homozygous populations. In late planting date, the two parents G.90 $\times$ CB.58 and G.95 had lint yield equal to or greater than means of blends (heterozygous populations). Adding to the two blends of inbreds, [((G.91 $\times$ G.90) $\times$ G.80) $]+[$ G.90 $\times$ CB.58] and $[((G .83 \times G .80) \times G .89) \times(G .83 \times$ Deltabine 703) $]+[G .90 \times$ CB.58] had the highest lint yield included the best inbred $(G$. $90 \times$ CB.58) suggesting that blend performance was determined by inbred performance.

Conclusions: Cotton blends may not provide buffering against late planting date. Blend response or heterotic response increased with late planting. However, cotton yields can sometimes be increased through the blends. Blends were not better than inbreds, and blend response was not consistent among the blends. Using blends is not recommended to increase yields or tolerance for late planting, and homozygous population's cultivars could result in increased yields relative to blends. Assuming an efficient method for producing homozygous population's cultivars was available, homozygous populations should be a viable option for commercial production to decrease observed losses in late planting date conditions.
\end{abstract}

Keywords: Cotton, Stress susceptibility index, Blend and heterotic response

\section{Background}

The planted area of Egyptian cotton and yield per unit area is decreasing. This is attributed to two main causes: (1) The farmers delay the planting date for a month after March 30 (the recommended sowing date) to get complete winter crop especially wheat before cotton. (2)

\footnotetext{
* Correspondence: seldessouky@yahoo.com

${ }^{2}$ Genetics and Cytology Department, Genetic Engineering and Biotechnology Research Division, National Research Centre, Dokki, PO Box 12622, Cairo,

Egypt

Full list of author information is available at the end of the article
}

The Egyptian cotton cultivars were bred as a full season crop (180 days) grown from mid-March to mid-September. Consequently, the Egyptian cotton cultivars cannot tolerate the environmental stress of late sowing and often result in progressively decreasing yield. Many reports emphasized the adverse effects of late planting on yield (Silvertooth 2001; Norton and Clark 2004; Mahdy et al. 2018). Cotton breeders initiated and advocated the need for considering the concept of double cropping of summer Egyptian cotton with winter crops. Nowadays, late planting system is considered an agricultural 
practice adopted by the Egyptian cotton farmers in some areas. This is usually done due to changing economics of Egyptian cotton production due to the high costs of inputs and low net income of outputs. Several publications in this topic were published (Abo El-Zahab et al. 2007 and 2008; Baker et al. 2012). Selection of different genotypes under environmental stress conditions is considered one of the main tasks of plant breeders for exploiting genetic variations to improve stress-tolerant cultivars (Clark et al. 1984). Schnell and Becker (1986) stated that the population structure type to be produced for commercial use is the breeder's decision. Moreover, breeding new varieties process nearly always implies that the genetic material passes through different several population structures before reaching the final one. These hints should sufficiently elucidate the relevance of examining the various population structures for the effects of the two factors, heterogeneity and heterozygosity, upon the yield level and yield stability.

Allard and Bradshaw (1964) attempted to detail environmental variation (aptly categorized into predictable and unpredictable variation) and what might quell it. They stated that a genetically heterozygous plant population will often have a greater chance of successful adaptation across a range of environments than a genetically homogeneous population. Also, they reported that diversity is considered as a form of buffering capacity that can be divided into individual buffering and population buffering. Individual buffering gets into the form of heterozygous genotypes that theoretically withstand change to the environment through allelic variation that produces complex enzymes with various optimal operating conditions or led to biochemical versatility that allows divergent biochemical pathways under different environmental conditions (Lewis 1954). Stelling et al. (1994) recorded a $23 \%$ improvement in the yield stability of the faba bean (Vicia faba L.) hybrid population compared with the pure line population, and also the blended hybrid population of faba bean was the most stable population (51\% increase). Opondo and Ombakho (1997) and Haussmann et al. (2000) found an increase in stability of blended entries when compared with individual blend components. Superiority of genotype blends over pure line cultivars has been observed in numerous crops, including wheat, soybean, oat, wheat, barley, flax, sorghum, maize, rice, and upland cotton (Becher et al. 2008). However, research in these crops has also indicated that the effects of blending genotypes vary. Smithson and Lenne (1996) observed that blended entries do not always increase the stability and they stated that blending may lead to no significant increase in yield, and it may even have negative effects in some cases.

Simpson and Fiori (1974) reported no effect on strength, strength variability, uniformity, and end breakage of mixing cotton seeds differ in micronaire prior to milling. Agi et al. (2001) and Durant (1995) studied planting cottonseed mixtures of two cultivars and its effect on insect pests. In Uganda, Innes (1977) found that yields of mixing numerous upland cultivars did not exceed monoculture yields. Bridge et al. (1984) observed that mixing two cultivars with similar yield potential did not gave differences in yield potential or staple length, but possible additive effects increased micronaire and lint strength. In Arkansas, McConnell et al. (1991) observed that mixing seed of Deltapine 50 and Deltapine 90 or DP 50 and Hyperformer 46 resulted in increasing strength values above DP 50 monocultures.

The objectives of this study were (1) to determine the impact of heterogeneity and heterozygosity on cotton lint yield stability of four cotton population types grown under late planting date and (2) to identify the suitable populations for cultivation at late planting areas of Middle and Upper Egypt.

\section{Materials and methods}

Five cotton genotypes (inbreds) were crossed in a half diallel design during the summer of 2016 to produce 10 hybrid combinations at Giza Agricultural Experiment Station, ARC. The genotypes were coded from 1 to 5 , and a single cross code is a combination of the two codes.

Four population types were used in this study.

I) Homogeneous population of homozygous plants: homozygous lines grown in pure stands viz. population included the five parents (inbreds) grown in pure stands.

II) Homogeneous population of heterozygous plants: the hybrids viz. population included the 10 hybrids $\left(\mathrm{F}_{1}\right)$ grown in pure stands.

III) Heterogeneous population of homozygous plants: homozygous lines grown in blended stands (blends of lines) viz. population included the parents grown in two-parent blends (midcomponent) resulting in 10 blended entries.

IV) Heterogeneous population of heterozygous plants: blends of hybrids viz. population was a combination of the two-hybrid blends (midcomponent); the arrangement is genetically balanced in that all four populations of entry share the same set of nuclear genes in equal frequencies (in this study, 1/5) according to Haussmann et al. (2000) resulting in five blended entries.

In the heterogeneous populations (III and IV), to ensure that the components of each blend were sown alternately in the successive hills of each plot and average two-hill (midcomponent) used to as seed cotton yield 
per plant. In 2017, field evaluation of four population types was made at two planting dates, i.e., April first for normal planting (NP) designated as non-stress conditions and May 15 for late planting (LP) designated as stress conditions at Giza Agric. Res. Station.

The experimental design was a randomized completeblock design with three replications. Plot size was one row of $0.6 \mathrm{~m}$ wide $\times 4 \mathrm{~m}$ long; spacing within rows was $0.25 \mathrm{~m}$ between hills with one plant by hill. The different agricultural practices for cotton plants under non stress conditions were kept at optimum levels throughout the growing season to obtain maximum productivity. However, the integrated production management (IPM) for late planting format as outlined by Abo El-Zahab (1994) was applied under stress conditions. Where double rows $60 \mathrm{~cm}$ apart system in beds, $120 \mathrm{~cm}$ apart were adapted. Early thinning 19 days after planting to one plant per hill was undertaken. PIX, a growth regulator of $1 \mathrm{l} / \mathrm{fed}$ at early flowering period, was applied.

At maturity, a random representative sample was picked from each plot for seed cotton yield component determination. Seed cotton sample was cleaned, weighed, and ginned, and the lint was weighed to determine lint percentage. The yield contributing traits were seed cotton yield/plant (SCY/P, g), lint cotton yield/plant (LCY/P), lint percentage (L \%), seed index (SI), and lint index (LI).

The fiber traits were determined from the lint per plot. These traits were fiber length, expressed by upper half mean (UHM) as $2.5 \%$ span length (millimeters), fiber length uniformity index (UR), fiber strength (Str), and micronaire reading (Mic $\mathrm{R}$ ) which representing the fiber fineness and maturity (May and Bridges 1995; ASTM 1998). These traits were tested at Cotton Technology Dep., Cotton Res. Inst., Agric. Res. Center. Designation and main fiber characteristics of the parents are presented in Table 1.

Stress susceptibility index (SSI) was calculated using the following relationship:

$\mathrm{SSI}=\left[1-\left(Y_{\mathrm{LP}} / Y_{\mathrm{NP}}\right)\right] / \mathrm{SI}$ (Fischer and Maurer 1978)

which SI (stress intensity) $=1-\left(\bar{Y}_{\mathrm{LP}} / \bar{Y}_{\mathrm{NP}}\right), Y_{\mathrm{NP}}$ is the genotype mean under normal planting date, $Y_{\mathrm{LP}}$ is the genotype mean under late planting date, $\bar{Y}_{\mathrm{NP}}$ and $\bar{Y}_{\mathrm{LP}}$ are the means of all genotypes under normal planting and late planting dates, respectively. The genotype with SSI $\leq$ $0.50=$ highly tolerant $(\mathrm{H}), 0.05<\mathrm{SSI} \leq 1.00=$ moderately tolerant $(\mathrm{M})$ and $\mathrm{SSI}>1.00=$ susceptible $(\mathrm{S})$ to late planting date according to Khanna-Chopra and Viswanathan (1999).

Blend response (BR) for the parent entries was calculated by subtracting the average of the two blend components (midcomponent) from the observed value of each blended entry. Mid-parent heterosis and heterotic response (HR) for the hybrid entries were calculated in a similar manner where the average of the two hybrid components (midcomponent) was subtracted from the value of the hybrid entry. Heterotic response for the blended hybrid entries was calculated by subtracting the average of the four parental components (midcomponent) that correspond to each blend from the observed value of each blended entry. Percent blend response (BR, $\%)$ and percent heterosis response (HR \%) were calculated by dividing the response of each measured entry by the midcomponent and multiplying by 100 .

\section{Results}

The analysis of variance results for all tested parameters across the two planting dates and combined are presented in Table 2. Genotypes had significant effects on all yield and yield components except lint percentage (L $\%$ in all three analysis and lint index (LI) in normal planting (NP) only. Planting date effects were significant for all traits. The genotype by planting date interactions were significant for all traits except L \% and LI indicating that they were sufficiently variable to measure yield stress susceptibility index (SSI). Further analysis indicated that the interaction is a product of the relationship between the hybrids and hybrid blends and their change in rank from low-yielding (LP) to high-yielding environments (NP).

Overall means of SCY and LCY traits varied among the two planting dates (Table 3). High SCY and LCY values were observed at NP with average yields of 150.2 and $60.1 \mathrm{~g} / \mathrm{p}$ compared with 119.5 and $46.2 \mathrm{~g} / \mathrm{p}$ at LP, respectively. In normal planting date (NP), means of LCY were $70.2,67.2,49.5$, and $56.8 \mathrm{~g} / \mathrm{p}$ for inbreds, hybrids,

Table 1 Designation and main characteristics of five Egyptian cotton genotypes

\begin{tabular}{|c|c|c|c|c|}
\hline \multirow[t]{2}{*}{ Designation } & \multicolumn{4}{|c|}{ Fiber characteristics } \\
\hline & UHM (mm) & UR (\%) & Mic R. (unit) & Str $(g /$ tex $)$ \\
\hline 1. $(\mathrm{G} .91 \times \mathrm{G} .90) \times \mathrm{G} .80\left(\mathrm{P}_{1}\right)$ & 31 & 82 & 4.3 & 9.4 \\
\hline 2. $[(G .83 \times G .80) \times G .89] \times[G .83 \times$ Deltabine 703$]\left(P_{2}\right)$ & 31 & 83 & 4.6 & 9.2 \\
\hline 3. $[(G .83 \times G .80) \times G .89] \times$ Australian $\left(P_{3}\right)$ & 31 & 82 & 4.7 & 9.1 \\
\hline 4. $\mathrm{G} .90 \times$ CB.58 $\left(\mathrm{P}_{4}\right)$ & 30 & 82 & 5.1 & 8.8 \\
\hline 5. G.95 $\left(P_{5}\right)$ & 30 & 81 & 4.4 & 9.3 \\
\hline
\end{tabular}

Spinning test report on the Egyptian cotton crop of 2018, reported by Cotton Research Institute, ARC, Egypt 
Table 2 Mean squares of four cotton populations genotypes cultivated in normal (NP) and late planting date (LP)

\begin{tabular}{|c|c|c|c|c|c|c|c|c|c|}
\hline \multirow[t]{2}{*}{ SV } & \multicolumn{3}{|c|}{ Seed cotton yield/plant; SCY/P (g) } & \multicolumn{3}{|c|}{ Lint cotton yield/plant; LCY/P (g) } & \multicolumn{3}{|c|}{ Bolls/Plant } \\
\hline & NP & LP & Combined & NP & LP & Combined & NP & LP & Combined \\
\hline PD & & & $42.424^{* *}$ & & & $8707.37 * *$ & & & $183.87^{* *}$ \\
\hline Rep. & 3.16 & $1.14^{* *}$ & $2.15^{*}$ & 739.15 & $170.52^{* *}$ & $369.57 *$ & 11.69 & 0.43 & $6.06 \mathrm{~ns}$ \\
\hline G & $3.33^{* *}$ & $5.26^{* *}$ & $2.59^{* *}$ & $540.77^{* *}$ & $805.30^{* *}$ & $380.25^{* *}$ & $18.37^{* *}$ & $24.73^{* *}$ & $11.75^{* *}$ \\
\hline$P D \times G$ & & & $6.00^{* *}$ & & & $974.82 * *$ & & & $31.34^{* *}$ \\
\hline Error & 1.68 & 32 & 857 & 295.79 & 4.74 & 147.89 & 8.80 & 0.54 & 4.67 \\
\hline $\mathrm{LSD}_{0.05}$ & & & 33.1 & & & 13.8 & & & 2.45 \\
\hline \multirow[t]{2}{*}{ SV } & \multicolumn{3}{|c|}{ lint percentage; L\% } & \multicolumn{3}{|c|}{ Seed index; SI (g) } & \multicolumn{3}{|c|}{ Lint index; LI (g) } \\
\hline & NP & LP & Combined & NP & LP & Combined & $N P$ & LP & Combined \\
\hline PD & & & $79.01^{* *}$ & & & $9.63^{* *}$ & & & $19.00^{* *}$ \\
\hline Rep. & $21.27 \mathrm{~ns}$ & $149.99^{*}$ & $85.63^{* *}$ & $1.45^{* *}$ & $1.15^{* *}$ & $1.30^{* *}$ & 3.83 & $6.79^{* *}$ & $5.31^{* *}$ \\
\hline G & $14.39 \mathrm{~ns}$ & $6.55 \mathrm{~ns}$ & $11.77 \mathrm{~ns}$ & $0.58^{* *}$ & $0.99^{* *}$ & $0.79^{* *}$ & $1.19 \mathrm{~ns}$ & $0.61^{* *}$ & $1.03^{*}$ \\
\hline$P D \times G$ & & & $9.17 \mathrm{~ns}$ & & & $0.78^{* *}$ & & & $0.76 \mathrm{~ns}$ \\
\hline Error & 11.78 & 5.02 & 8.40 & 0.03 & 0.00 & 0.01 & 0.85 & 0.26 & 0.56 \\
\hline $\mathrm{LSD}_{0.05}$ & ns & ns & ns & & & 0.13 & ns & 0.84 & 0.84 \\
\hline
\end{tabular}

$\mathrm{Ns}^{*}{ }^{*}$, and ${ }^{* *}$ denote not significant, significant differences at 0.05 and 0.01 levels of probability, respectively

blend of inbreds, and blend of hybrids, respectively. In late planting date (LP), means of LCY were 46.9, 35.1, 55.9 and $48.2 \mathrm{~g} / \mathrm{p}$ for the four populations.

In Upland cotton, Becher et al. (2008) study the effect of different cotton cultivars blending on fiber quality, lint yield, and lint yield stability under irrigated and dry land conditions. They found that the yields of the blends were intermediate between the low and high yielding cultivars. Blending had no effect on fiber strength, but uniformity was reduced by blending. Some blends showed better stability and adaptation across environments compared with their components. Blending of cultivars might serve as a short-term alternative, but it cannot substitute for the breeding of cotton cultivars with both high yield and high fiber quality. Faircloth et al. (2003) arrived at a similar conclusion. The genotype by environment interaction and stability analyses of the data, however, indicate that some blends have better adaptation and stability across environments compared with their individual components. In general, the blends produce greater lint yield than their individual components in favorable environments. Some cultivars also do better in blends than other cultivars.

Cole et al. (2009) found that "in Upland cotton," no significant difference between lines grown in pure stands and blended lines with respect to stability or yield. Hybrids were more stable than homozygous lines. This stability was attributed to the hybrids and blends of hybrids out-yielding the homozygous lines and blends of homozygous lines in the low-yielding environments, but having similar yields in the high-yielding environments. These results do not support growing blends to increase yield or stability. However, growing hybrid cultivars could result in increased yields while reducing variability compared with usual production practices.

In Egypt, AL-Bana et al. (2010) blended extra-long and long Egyptian cottons for producing high-quality yarns. They found that it is possible to blend up to $50 \%$ of Giza 88 lint as extra-long staple cotton with $50 \%$ Giza 80 as long staple cotton without any pronounced decrease in single yarn strength and unevenness value weather spun at compact and ring spinning at different yarn counts under study.

In normal planting date (NP), overall mean lint cotton yield (LCY), blend response (BR \%), and heterotic response (HR \%) were $60.1 \mathrm{~g} / \mathrm{p},-28.6 \%$, and $-10.0 \%$, respectively. However, in late planting date (LP), the values of the same traits were $46.2 \mathrm{~g} / \mathrm{p}, 25.2 \%$, and $52 \%$, respectively (Table 4).

In LP, cotton yields of all 30 genotypes were significantly lower than its counterpart in NP (Table 3). Late planting stress reduced SCY, LCY, bolls/P, L\%, SI, and LI by $20.4,23.1,18.9,3.3,4.4$, and 11.5 , respectively. The largest reductions in LCY due to the stress of LP were observed for the inbreds (33.2\%) and hybrids (47.8\%), whereas the lowest reductions were detected in blend of hybrids (15.1\%). This was reflected in higher sensitively stress indices for inbreds (SSI $=1.1$ or susceptible) and hybrids (SSI $=2.0$ or susceptible). However, reductions for blend of inbreds $(-12.9 \%)$ superior in LP than NP (SSI $=-0.6$ or high stress tolerant) and blend of hybrids (15.1\%) superior in LP than NP $(\mathrm{SSI}=0.4$ or high stress tolerant). Adding to blend of inbreds revealed blend response (25.2\%), and blend of hybrids revealed heterotic 


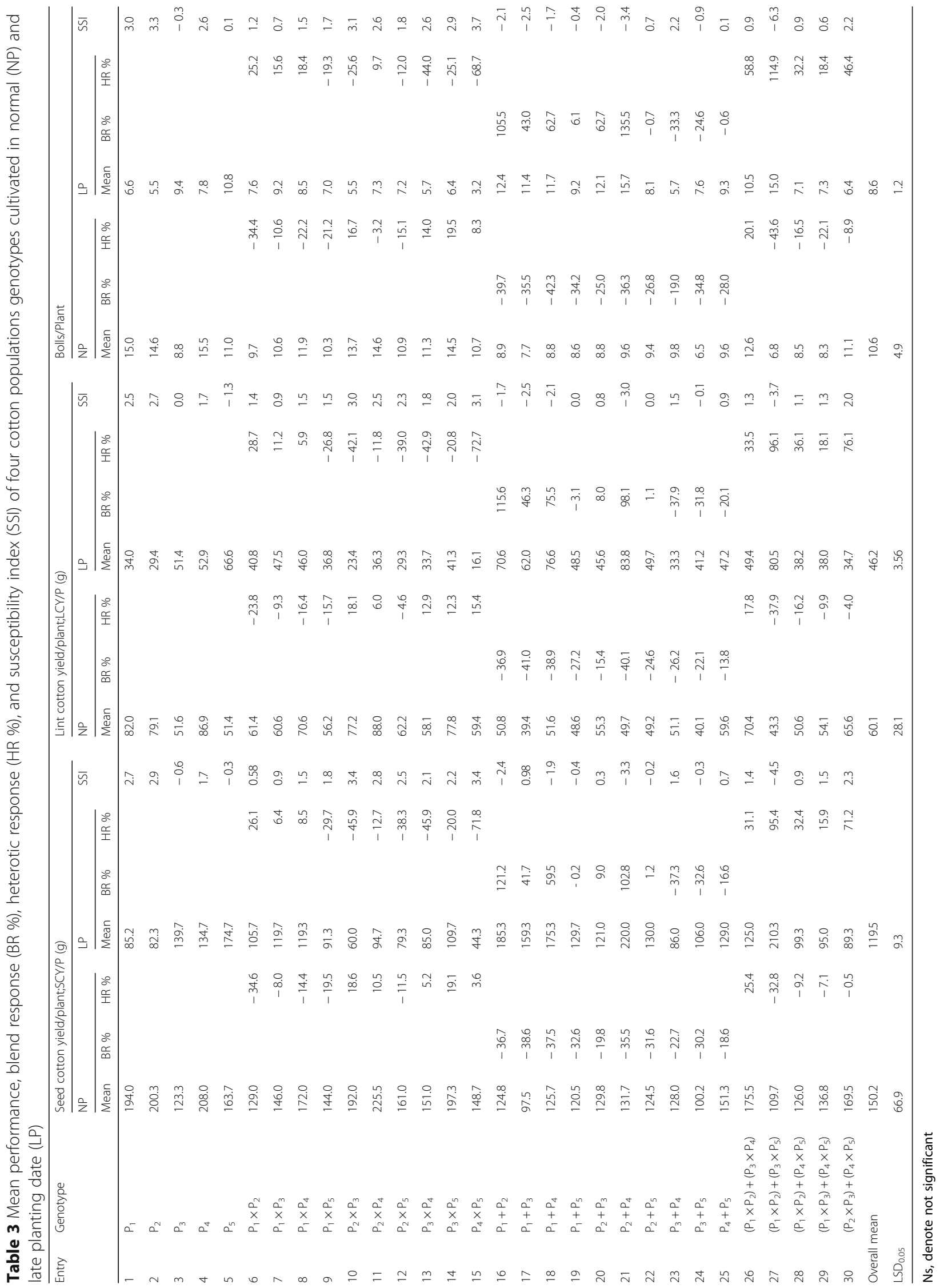




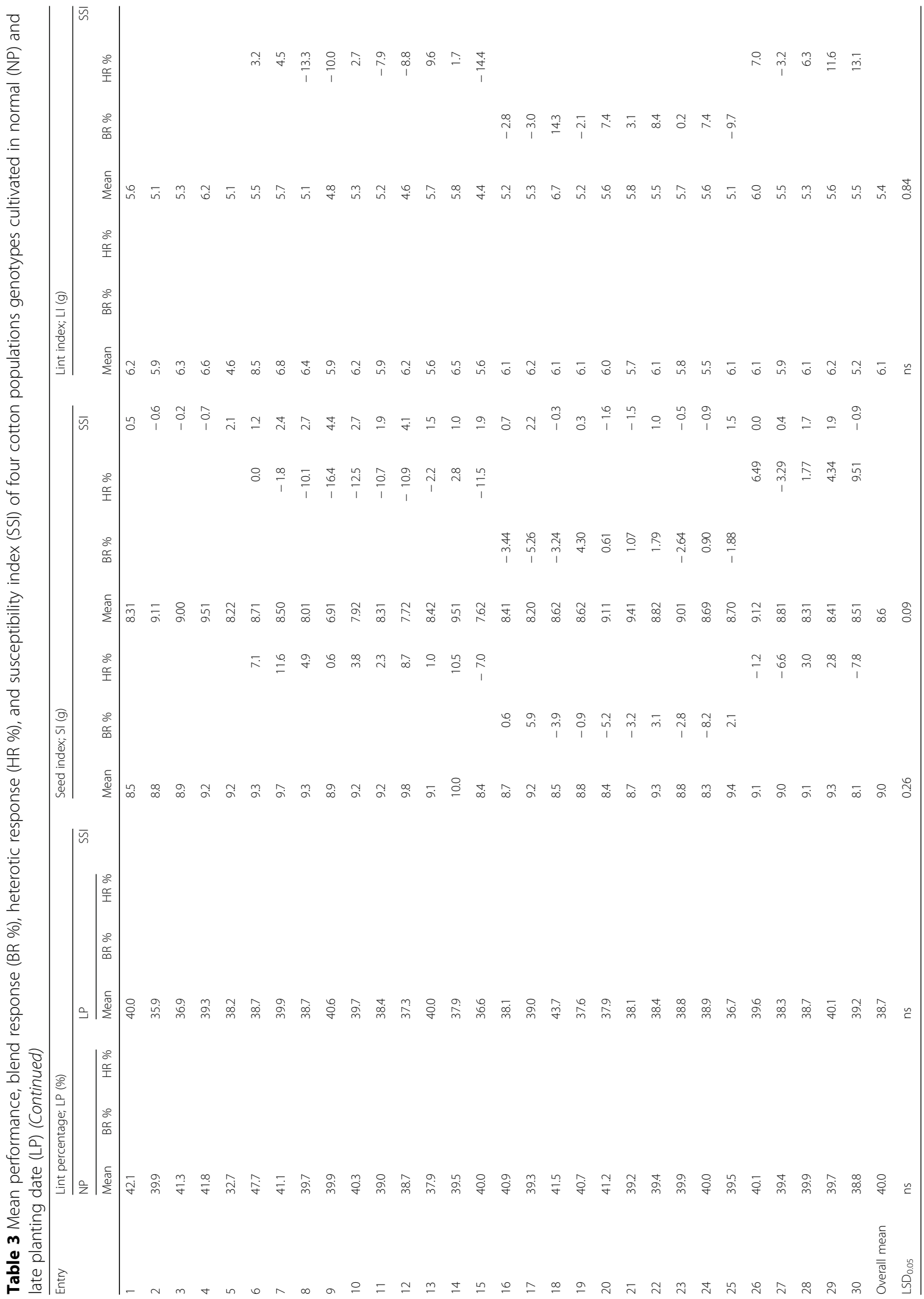


Table 4 Grand mean performance, blend response (BR \%), heterotic response (HR \%) and susceptibility index (SSI) for four populations of cotton genotypes cultivated in normal and late planting date

\begin{tabular}{|c|c|c|c|c|c|c|c|c|c|c|c|c|c|c|}
\hline \multirow[t]{2}{*}{ Genotype } & \multicolumn{3}{|l|}{ NP } & \multicolumn{3}{|l|}{ LP } & \multirow[t]{2}{*}{ SSI } & \multicolumn{3}{|l|}{ NP } & \multicolumn{3}{|l|}{ LP } & \multirow[t]{2}{*}{ SSI } \\
\hline & Mean & BR \% & $H R \%$ & Mean & $\mathrm{BR} \%$ & $H R \%$ & & Mean & BR \% & $\mathrm{HR} \%$ & Mean & BR \% & $\mathrm{HR} \%$ & \\
\hline & \multicolumn{7}{|c|}{ Seed cotton yield/plant; SCY/P (g) } & \multicolumn{7}{|c|}{ Lint cotton yield/plant; LCY/P (g) } \\
\hline Inbreds & 177.9 & & & 123.3 & & & 1.3 & 70.2 & & & 46.9 & & & 1.1 \\
\hline Hybrids & 166.7 & & -3.1 & 90.9 & & -22.3 & 2.1 & 67.2 & & -0.5 & 35.1 & & -21.0 & 2.0 \\
\hline Blends of inbreds & 123.4 & -30.4 & & 144.2 & 24.9 & & -0.9 & 49.5 & -28.6 & & 55.9 & 25.2 & & -0.6 \\
\hline Blends of hybrids & 143.5 & & -4.9 & 86.1 & & 49.2 & 0.4 & 56.8 & & -10.0 & 48.2 & & 52.0 & 0.4 \\
\hline Overall mean & 150.2 & & & 119.5 & & & & 60.1 & & & 46.2 & & & \\
\hline \multirow[t]{2}{*}{$\operatorname{LSD}_{0.05}$} & 66.9 & & & 9.3 & & & & 28.1 & & & 3.56 & & & \\
\hline & \multicolumn{7}{|c|}{ Bolls/Plant } & \multicolumn{7}{|c|}{ Lint percentage; LP (\%) } \\
\hline Inbreds & 13.0 & & & 8.0 & & & 1.7 & 39.6 & & & 38.1 & & & \\
\hline Hybrids & 11.8 & & -4.8 & 6.0 & & -12.6 & 2.2 & 40.4 & & & 38.8 & & & \\
\hline Blends of inbreds & 8.8 & -32.2 & & 9.3 & 15.3 & & -1.0 & 40.2 & & & 38.7 & & & \\
\hline Blends of hybrids & 9.5 & & -14.2 & 9.3 & & 54.1 & -0.3 & 39.6 & & & 39.2 & & & \\
\hline Overall mean & 10.6 & & & 8.6 & & & & 40.0 & & & 38.7 & & & \\
\hline \multirow[t]{2}{*}{$\mathrm{LSD}_{0.05}$} & 4.9 & & & 1.2 & & & & ns & & & ns & & & \\
\hline & \multicolumn{7}{|c|}{ Seed index; SI (g) } & \multicolumn{7}{|c|}{ Lint index; LI (g) } \\
\hline Inbreds & 8.9 & & & 8.8 & & & 0.2 & 5.9 & & & 5.5 & & & \\
\hline Hybrids & 9.3 & & 4.4 & 8.3 & & -7.3 & 2.1 & 6.4 & & & 5.1 & & -3.3 & \\
\hline Blends of inbreds & 8.9 & -1.8 & & 8.9 & -0.15 & & -0.1 & 6.0 & & & 5.5 & 1.9 & & \\
\hline Blends of hybrids & 8.9 & & -2.0 & 8.6 & & 3.8 & 0.6 & 5.9 & & & 5.6 & & 7.0 & \\
\hline Overall mean & 9.0 & & & 8.6 & & & & 6.1 & & & 5.4 & & & \\
\hline $\mathrm{LSD}_{0.05}$ & 0.3 & & & 0.1 & & & & ns & & & 0.8 & & & \\
\hline
\end{tabular}

response (52\%) in LP for high potential yielding ability (Table 4). Therefore, heterogeneity populations (blend of inbreds and blend of hybrids) are of much important as to be involved in breeding program for tolerance to late planting stresses.

The two low-yield potential parents, $\mathrm{P}_{3}$ in SCY (NP $=123.3 \mathrm{~g}, \mathrm{LP}=139.7 \mathrm{~g}$, and $\mathrm{SSI}=-0.6)$ and in $\mathrm{LCY}$ $(\mathrm{NP}=51.6 \mathrm{~g}, \mathrm{LP}=51.4 \mathrm{~g}$, and $\mathrm{SSI}=0.0)$ and $\mathrm{P}_{5}$ in $\mathrm{SCY}$ $(\mathrm{NP}=163.7 \mathrm{~g}, \mathrm{LP}=174.7 \mathrm{~g}$, and $\mathrm{SSI}=-0.3)$ and in $\mathrm{LCY}(\mathrm{NP}=51.4 \mathrm{~g}, \mathrm{LP}=66.6 \mathrm{~g}$, and $\mathrm{SSI}=-0.7)$ were identified rated as high stress tolerant $(\mathrm{H})$ parents. However, the parent $\mathrm{P}_{4}$ in $\mathrm{LCY}(\mathrm{SSI}=0.8)$ was classified as intermediate $(\mathrm{M})$ parent. The remaining parents $P_{1}$ and $P_{2}$ were classified as susceptible $(S)$ in their stress tolerance to late planting date (Table 3). The results indicated that the stress tolerance of the two parents $\mathrm{P}_{3}$ and $\mathrm{P}_{5}$ may be due mainly to the stress tolerant of bolls/plant plus seed index in case of $\mathrm{P}_{3}$ (Table 3 ). Hybrid $\left(\mathrm{P}_{4} \times \mathrm{P}_{5}\right)$ had the lowest lint yield stress tolerant or susceptible $(\mathrm{SSI}=3.1)$ for late planting date and the lowest mid-parent heterosis ($72.7 \%)$ observed for the low-yielding environment (LP). Hybrid $\left(\mathrm{P}_{1} \times \mathrm{P}_{3}\right)$ had intermediate lint yield stress tolerant $(\mathrm{SSI}=0.9)$, and the second highest mid-parent heterosis (11.2\%) indicating that heterosis cannot explain all of the variations observed in yield stress tolerant for the hybrid genotypes.

In late planting date (LP), the greatest-yielding inbreds (entry 4 and 5 or $\mathrm{P}_{4}$ and $\mathrm{P}_{5}$ ) had LCY (52.9 and $66.6 \mathrm{~g} / \mathrm{p}$ ) equal or greater than means of blends (heterozygous populations), 55.9 and $48.2 \mathrm{~g} / \mathrm{p}$ for blend of inbreds and blend of hybrids, respectively (Table 3). These results suggest that cotton blends may not provide buffering against stressful environments (late planting date), if appropriate blends are chosen. In late planting date, the blends of inbreds with the highest LCY (entry 18 with 76.6 and entry 21 with $83.8 \mathrm{~g} / \mathrm{p}$ ) included the best inbred (entry 4; $\mathrm{P}_{4}$ ), adding to blends of hybrids with the highest LCY (entry 27 with $80.5 \mathrm{~g} / \mathrm{p}$ ), no difference between them and entry 21 suggesting that blend performance was largely determined by inbred performance. Because the highest ranked entries for LCY were inbred cultivars and because LCY may be important to farmers, blending may have unfavorable effects on LCY. 


\section{Discussion}

Homozygous entries (inbreds and hybrids) significantly out yielded heterozygous entries in normal planting date. Thus, in normal planting date, means of LCY for homozygous entries are greater than mean yields of heterozygous entries. These results do not support growing blends to increase yield. Thus, in late planting date, the mean of LCY for heterozygous entries was greater than or equal mean yields of homozygous entries and it was found that no significant difference between inbreds and blend of hybrids with respect to yield. This result due to means of bolls/plant for these populations was greater than other populations.

Improvement in lint yield may stem from the ability of each heterozygous genotype to yield well in unfavorable environments (late planting date).

Blend response or heterotic response increased as environmental yields decreased. Thus, mean blend response or heterotic response and planting date mean yield were negatively correlated. This is congruent with Cole et al. (2009) who found that cotton blending response increased in stressful environments (late planting date).

There was an association between heterotic response and environment mean, and each effect had on stress susceptibility index (SSI). The exact interaction is difficult to predict with these data. One can clearly see that heterotic response increased as environmental yields decreased. This may be attributed to a physiological response for mid-components in two environments that become less advantageous with increasing environmental quality. For example, a faster growing mid-component populations could take full advantage of favorable environmental conditions (normal planting, NP) early in the season and better tolerate unfavorable conditions (late planting, LP) occurring later in the season. This could result in increased yields and tolerance to late planting relative to the inbreds (population 1). The opposite of this would occur under favorable environmental conditions where any advantage associated with increased rate of growth would be negated by inbred genotypes exploiting a full season of favorable conditions (Went 1953). Wells et al. (1988) observed leaf area and plant photosynthesis in hybrid and inbred genotypes and attributed increased leaf area index of the hybrids to increased growth during the seedling stage. Leaf area and photosynthesis measurements taken early in plant development were significantly correlated. During the early stages of development, hybrids had faster growth, bigger plants, and better light interception resulting in more photosynthate production. Wells and Meredith (1986) found hybrids produced more lint and matured earlier than inbred genotypes. Final leaf area index and total dry weight of hybrids were also greater than the inbreds, and this was attributed to the faster growth rate of hybrids during the seedling stage. Our results indicated that cotton yields can sometimes be increased through the blending of particular parents or hybrids. However, all blends were not better than all inbreds, and blend response was not consistent among all blends. So, methods for identifying superior blends would be helpful to plant breeder. Stress susceptibility index (SSI) statistic was used to measure the adaptability of the entries to determine if any cotton populations results in improved tolerance to late planting date of yield.

With respect to yield and SSI, there were differences between the homogeneous (inbred and hybrids) and heterogeneous (blend of inbreds and blend of hybrids) populations. The heterozygous populations had tolerance for late planting date than the homozygous populations.

SSI for yield components related traits (Table 3) revealed that bolls/P followed by SI are the main components for the SSI tolerance for yielding potential of aforementioned heterogeneity populations. So, the breeder must be taken bolls/P and SI consideration when selecting for yielding ability under late planting stress conditions. These results are in agreement with Baker et al. (2012). Mahdy et al. (2018) found that the reduction percentage in lint yield/plant was 23.21 and $23.87 \%$ for the parents and $F_{1}$ hybrids, respectively. In this connection, Niles $(1969,1974)$ in the USA observed that "short-season" strains flowered earlier had more rapid flowering rates, and exhibited earlier boll maturity when compared with standard cultivars. Even though "short-season" strains possessed fewer fruiting sites and produced less lint yield/plant (Niles 1974; Quisenberry 1977).

Hybridization is the most breeding procedure for producing new cotton cultivars. In Egypt, a pedigree selection procedure is generally followed during the segregating generations. Selection is terminated at an early generation while some heterozygosity still remains, rarely being pursued until homozygosity is reached. Lines genetically different, yet uniform for plant type, disease and insect resistance, and fiber properties, are pooled to form the new cultivar. The process of breeding new varieties nearly always implies that the genetic material passes through structures of several different populations before reaching the final one. For example, the Egyptian breeder usually hybridization starts from base populations of type I (inbred lines or varieties), then type II $\left(\mathrm{F}_{1}\right)$, then type IV, and gradually transforms them into type $\mathrm{I}$ in $\mathrm{F}_{6}$ generation.

\section{Conclusion}

It could be concluded that using blends is not recommended to increase yields; however, these results indicated that growing homozygous population's cultivars could result in increased yields relative to blended lines. 
Growing homozygous population's cultivars would allow farmers to utilize more diverse environments or to mitigate losses during environmentally stressful years. Assuming an efficient method for producing homozygous population's cultivars was available, homozygous populations should be a viable option for commercial production to decrease observed losses in low-yielding environments.

\section{Acknowledgements}

The authors would like to acknowledge Cotton Research Institute, ARC, Egypt for providing the plant materials and facilities needed for the present research.

\section{Funding}

Cotton Research Institute, ARC, Egypt provided the plant materials and facilities needed for the present research.

\section{Availability of data and materials}

The datasets used and/or analysed during the current study are available from the corresponding author on reasonable request.

\section{Authors' contributions}

All authors contributed in the conception and development of the research. KMAB performed initial crossings and experiments and was a major contributor. SEIE extended the analysis and wrote the paper. All authors read and approved the final manuscript

\section{Ethics approval and consent to participate}

Not applicable.

\section{Consent for publication}

Not applicable

\section{Competing interests}

The authors declare that they have no competing interests.

\section{Publisher's Note}

Springer Nature remains neutral with regard to jurisdictional claims in published maps and institutional affiliations.

\section{Author details}

${ }^{1}$ Cotton Research Institute, Agricultural Research Centre, Giza, Egypt. ${ }^{2}$ Genetics and Cytology Department, Genetic Engineering and Biotechnology Research Division, National Research Centre, Dokki, PO Box 12622, Cairo, Egypt.

Received: 10 August 2018 Accepted: 4 January 2019

Published online: 25 January 2019

\section{References}

Abo El-Zahab AA (1994). Integrated short-season production system for Egyptian cotton. Final Report. NARP Research Grant No. (34) A-6-8.

Abo El-Zahab AA, Awad HY, Baker KMA (2007) Prospective for breeding short season cotton. A second look. I combining ability for yield and yield related traits. Egypt J Plant Breed 11(3):1-22

Abo El-Zahab AA, Gomaa MAM, Amein MMM, Eldessouky SEl (2008) Differential mean performance of 9-parental cotton diallel cross progenies in full and short season environments. 1. Planting seed quality. Egypt. J. Plant Breed 12(1):87-113.

Agi AL, Mahaffey JS, Bradley JR Jr, Van Duyn JW (2001) Efficacy of seed mixes of transgenic Bt and nontransgenic cotton against bollworms, Helicoverpa zea Boddie [online]. J Cot Sci 5(2):74-80,

AL-Bana MN, EL-Sayed MAM, Ibrahim IAE, Nassar EMAA (2010) Blending extralong and long Egyptian cottons for producing high quality yarns. J Adv Agric Res 15(4):1013-1027.

Allard R, Bradshaw AD (1964) Implications of genotype-environmental interactions in applied plant breeding. Crop Sci 4:503-508.
ASTM (1998). Designation D. 1445-95 and 1447-89. Vol. 07.01 Easton, MD, USA. Baker KMA, El-Fesheikawy ABA, Khalifa HS (2012) Evaluation late planting stress tolerance indices for some cotton genotypes. Egypt J Plant Breed 16(4):61-74.

Becher E, Alexander A, Auld DL, Downer CP (2008) Effect of cultivar blends on fiber quality, lint yield and gross return of upland cotton in West Texas. J. Cotton Sci. 12:8-15.

Bridge RR, Miller SR, Lane SM (1984). The influence of binary seed mixtures of 'Stoneville 825 ' and 'Deltapine 41 ' cotton cultivars on their performance. Bull \# 931. Miss. Agric. For. Exp. Stn., Mississippi State, MS.

Clarke JM, Townley-Smith TF, McCaig TN, Green DG (1984) Growth analysis of spring wheat cultivar as varying drought resistance. Crop Sci 24:537-541.

Cole CB, Bowman DT, Bourland FM, Caldwell WD, Campbell BT, Fraser DE, Weaver DB (2009) Impact of heterozygosity and heterogeneity on cotton lint yield stability. Crop Sci 49:1577-1585.

Durant JA (1995) Efficacy of selected seed mixes of transgenic Bt and nontransgenic cotton against bollworms and tobacco budworms in South Carolina. In: Proc. Beltwide Cotton Conf., San Antonio, TX, 4-7 Jan. 1995. Natl. Cotton Counc. Am, Memphis, pp 769-771.

Faircloth JC, Edmiston K, Wells R, Stewart A (2003) Planting cotton cultivar mixtures to enhance fiber quality. J Cotton Sci 7:51-56.

Fischer RA, Maurer R (1978) Drought resistance in spring wheat cultivars. Part 1 : grain yield response. Augt. J Agric Res 29:897-912.

Haussmann BIG, Obilana AB, Ayiecho PO, Blum A, Schipprack W, Geiger HH (2000) Yield and yield stability of four population types of grain Sorghum in a semi-arid area of Kenya. Crop Sci 40:319-329.

Innes NL (1977) Performance of seed mixtures and multilines of upland cotton in Uganda. J Agric Sci (Cambridge) 88:47-54.

Khanna-Chopra R, Viswanthan C (1999) Evaluation of heat stress tolerance in irrigated environment of T. aestivum and related species. I. Stability in yield and yield components. Euphytica 106:169-180.

Lewis D (1954) A relationship between dominance, heterosis, phenotypic stability and variability. Heredity 8:333-356.

Mahdy EE, Abo-Elwafa A, Abd El-Zaher GH, Sayed MA, Hosein MG (2018) Genetic Analysis of earliness and lint yield under normal and late sowing dates in Egyptian cotton. Egypt. J. Agron 40(1):31-44.

May OL, Bridges BC Jr (1995) Breeding cottons for conventional and late-planted production systems. Crop Sci 35:132-136.

McConnell JS, Bourland FM, Frizzel BS, Baker WH (1991) Enhanced cotton fiber strength through the use of blended cultivars. Arkansas Farm Res 40(5):3.

Niles GA (1969) Growth and fruiting modification for mechanized production. In: Brown JM (ed) Proc. Beltwide Cotton Prod. Conf., New Orleans, LA, 7-8 Jan. National Cotton Council, Memphis, pp 114-117.

Niles GA (1974) Growth and fruiting characteristics of short-season cottons. mechanized production. In: Brown JM (ed) Proc. Beltwide Cotton Prod. Conf., Dallas, TX, 7-9 Jan. National Cotton Council, Memphis, p 80.

Norton RR, Clark LJ (2004). Planting date by variety evaluation in Graham Country. Cotton Univ of Arizona Report P-138 pp 16-24.

Opondo RM, Ombakho GA (1997) Yield evaluation and stability analysis in newly selected'KSA' cotton cultivars in western Kenya. Afr Crop Sci J 5:119-125.

Quisenberry JE (1977) Inheritance of plant height in cotton. I. Diallel analysis among six semidwarf strains. Crop Sci 17:347-350.

Schnell FW, Becker HC (1986) Yield and yield stability in a balanced system of widely differing population structures in Zea mays L. Plant Breed 97:30-38.

Silvertooth, J.C. (2001). General maturity groups for cotton varieties. Cotton Univ. of Arizona Report Series.

Simpson J, Fiori LA (1974) Effect of mixing cottons differing in micronaire reading and carding variables on cotton sliver quality, yarn properties, and end breakage. Textile Res J 44(5):327-331.

Smithson JB, Lenne JM (1996) Varietal mixtures: a viable strategy for sustainable productivity in subsistence agriculture. Ann Appl Biol 128:127-158.

Stelling D, Ebmeyer E, Link W (1994) Yield stability in faba bean, Vicia faba L:: 2. Effects of heterozygosity and heterogeneity. Plant Breed 112:30-39.

Wells R, Meredith WR Jr (1986) Heterosis in upland cotton: I. Growth and leaf area partitioning. Crop Sci 26:1119-1123.

Wells R, Meredith WR Jr, Williford JR (1988) Heterosis in upland cotton: II. Relationship of leaf area to plant photosynthesis. Crop Sci 28:522-525.

Went FW (1953) Gene action in relation to growth and development: I. phenotypic variability. Proc Natl Acad Sci U S A 39:839-848. 